\title{
Clinical Epidemiology and Antibiogram of UTI Patients Attended Different Hospital in Khartoum, Sudan
}

\author{
Ali Mohamed Badri ${ }^{1^{*}}$ and Sameer Ghorashi Mohamed ${ }^{2}$ \\ ${ }^{* 1}$ Department of Microbiology, Faculty of Medical Laboratory Sciences, International University of Africa, PO Box 2469, Khartoum, Sudan \\ ${ }^{2}$ Faculty of Medical Laboratory Sciences, International University of Africa, PO Box 2469, Khartoum, Sudan
}

"Corresponding author: Ali Mohamed Badri, Department of Microbiology, Faculty of Medical Laboratory Sciences, International University of Africa, PO Box 2469, Khartoum, Sudan, Tel: 249922233425; E-mail: ali.almhasi@gmail.com

Received date: September 14, 2017; Accepted date: October 04, 2017; Published date: October 06, 2017

Copyright: ( 2017 Badri AM, et al. This is an open-access article distributed under the terms of the Creative Commons Attribution License, which permits unrestricted use, distribution, and reproduction in any medium, provided the original author and source are credited.

\begin{abstract}
Urinary tract infections are the most common bacterial infections in humans, both as community-acquired and healthcare-associated infections. The present study was aimed to determine the distribution and antimicrobial susceptibility of strains isolated from urinary tract infections. A hospital cross-sectional based study includes 150 clinically suspected cases of urinary tract infections attended different hospital in Khartoum. Midstream urine samples were collected and pure isolates of pathogenic microorganisms were characterized by colony morphology, gram-stain and standard biochemical procedures. A standard method of agar disc diffusion susceptibility testing method was used to determine susceptibility patterns of the isolates. The most common pathogens isolated were $E$. coli $(57.3 \%)$, K. pneumonia $(16.7 \%)$, P. aeruginosa (14\%), E. feacalis (4\%). C. albicans ( $8 \%)$. For all UTI isolates, least resistance was observed, E. coli and Klebsiella pneumoniae showed the highest percentage of resistance to ampicillin, Cefepime, Amikacin and Ciprofloxacin, followed by Gentamycin and Imipenem. Significant bacteriuria has been observed. Majority of the isolates were resistant to the commonly prescribed antibiotics. Identifying the pathogen, choosing correct antibiotics, limiting their excess use, improving resistance surveillance systems will help controlling this global problem.
\end{abstract}

Keywords: Urinary tract infection; Antimicrobial susceptibility; Khartoum; Sudan

\section{Introduction}

Urinary tract infections are the most common bacterial infections in humans, both as community-acquired and healthcare-associated infections. It is the most common nonsurgical nosocomial infection in postoperative patients and the second most common healthcare associated infection $[1,2]$. As the second most common reason for empirical antibiotic treatment, UTI is a major driver of antibiotic usage globally [3]. It has a wide spectrum of severity and even though a usually benign infection, occurrence of a UTI in a surgical patient is associated with a threefold increase in death during hospitalization [4]. Hence, the prevention and treatment of UTI is therefore of great concern for the survival and wellbeing of the individual surgical patient. UTI's are classified as either lower (confined to the bladder) or upper (pyelonephritis), and as either uncomplicated or complicated. Predisposing factors for UTI include structural and functional abnormalities, foreign bodies, metabolic abnormalities, impaired immunity and urological surgery and instrumentation [3]. Indwelling catheter use is a known risk factor for UTI, with duration of catheterization as the single most important risk factor [3]. The bacteria are often of several different species, often multi-resistant [4]. Catheter-associated UTI make up a large proportion (approximately $30-40 \%$ ) of the healthcare-associated infections, and as many as $10 \%$ of patients in a urological wards have healthcare-associated complicated infections [3]. Urinary tract infection can be either symptomatic or asymptomatic. Patients with significant bacteriuria and have at least two symptoms referable to the urinary tract infection (dysuria, urgency, frequency, incontinence, suprapubic pain, flank pain or costovertebral angle tenderness, fever (temp $\geq 38^{\circ} \mathrm{C}$ ) and chills are said to be symptomatic. Asymptomatic bacteriuria (ABU) is a condition which is characterized by presence of bacteria in two consecutive clearvoided midstream urine specimens both yielding positive cultures ( $\geq$ $10^{5} \mathrm{cfu} / \mathrm{ml}$ ) of the same uropathogen, in a patient without classical symptoms of UTI [5].

Complications of UTI include urosepsis, renal impairment, and renal abscess. Underlying renal disease, diabetes mellitus, and immune suppression may worsen prognosis, but there is no good long term evidence about rates of sepsis or death among people with such conditions [6].

In contrast to men, women are more susceptible to UTI, and this is mainly due to short urethra, absence of prostatic secretion, pregnancy and easy contamination of the urinary tract with fecal flora [7].

Studies conducted in Ethiopia and other parts of the world showed that $E$. coli is the major etiologic agent in causing UTI, which accounts for up to $90 \%$ of cases [8-11]. Proteus mirabilis, Klebsiella species, Pseudomonas aeruginosa and Enterobacter species are less frequent offenders of Gram negative bacteria. Less commonly, Enterococci and Ureaplasma urealyticum are also known causative agents in UTIs. Gram-positive organisms are even less common in which Group B Streptococcus, Staphylococcus aureus, Staphylococcus saprophyticus and Staphylococcus haemolyticus are the recognized organisms [5]. Other less common uropathogens include Mycobacterium tuberculosis, which can arise via haematological inoculation rather than ascending infection. Nonbacterial causes include Chlamydia species and fungal infections, such as Candida albicans [12].

Antimicrobial resistance is emerging as an important public health problem in both the hospitals and the community. Untreatable 
infections are being recognized more frequently and, as important bacterial pathogens become increasingly resistant, the lack of new or alternative antimicrobial agents makes serious outbreaks a possibility [13]. This present study was to determine the distribution and antimicrobial susceptibility of strains isolated from urinary tract infections.

\section{Materials and Methods}

\section{Collection of urine samples}

This study is a cross-sectional study. One hundred and fifty Urine samples were collected from a Different hospital in Khartoum including; Khartoum, Asia, Soba, Omdurman, Bahry, Ibrahim Malik and Arm Forces Medical Hospitals and transported to the laboratory in an ice cold condition after adding boric acid at a final bacteriostatic concentration of $1.8 \%$ without delay [14].

\section{Data collection}

A structured closed ended questionnaire was used for data collection; also results of laboratory investigations of patients were collected.

\section{Ethical consideration}

This study was approved by the ethical committee of the International University of Africa, Faculty of Medical Laboratory Sciences. Permission from Medical Director Asia, Soba, Omdurman, Bahry, Ibrahim Malik and Arm Forces Medical Hospitals was applied and verbal consent was obtained from all subjects enrolled in the study.

\section{Isolation and identification of bacteria from urine samples}

Using calibrated wire inoculating loop $(0.001 \mathrm{ml})$ urine samples were inoculated into Cystine Lactose Electrolyte Deficient medium (Oxoid, Ltd., Basingstoke, Hampshire, England). CLED medium is recommended for diagnostic urinary bacteriology because it supports the growth of both gram positive and gram negative urinary potential pathogens and gives good colonial differentiation. Cultures were incubated in aerobic atmosphere at $37^{\circ} \mathrm{C}$ for $24 \mathrm{~h}$. Colonies were counted to check the presence of significant bacteriuria. colonies were selected and characterized on the basis of morphological, cultural and biochemical features and identified with the help of Bergey's Manual of Systemic Bacteriology [15].

\section{Antimicrobial susceptibility testing}

The antimicrobial susceptibility testing of all identified isolates was done according to the criteria of the Clinical and Laboratory Standards Institute method (CLSI) [16], from a pure culture a loopful bacterial colonies was taken and transferred to a tube containing $5 \mathrm{ml}$ of normal saline and mixed gently until it forms homogenous suspension. The turbidity of the suspension was then adjusted to the density of McFarland $0.5 \mathrm{~g}$ in order to standardize the inoculum size [16]. A sterile cotton swab was then deep into suspension and the excess was removed by gentle rotation of the swab against the surface of the tube. The swab was then used to distribute the bacteria evenly over the entire surface of Muller Hinton agar. The inoculated plates were left at room temperature to dry for 3-5 $\mathrm{min}$ [16]. With the aid of sterile forceps, the antibiotic disc was put on the surface of Muller-Hinton agar (Oxoid). The plates were then incubated at $37^{\circ} \mathrm{C}$ for $24 \mathrm{~h}$. Diameters of the zone of inhibition around the discs were measured using a digital caliper, and the isolates were classified as sensitive and resistant according to the standardized table supplied by CLSI 2014.

\section{Data analysis}

Data were entered and organized into Microsoft Office Excel 2007 data sheet, then subjected to statistical analysis using the software statistical package for social science program (SPSS) version 16.

\section{Results}

A total of One hundred and fifty Urine samples 60 males and 90 females (Table 1) with mean age of 39 years, in range from 4-75 years. (Figure 1) collected from patient's attendant a different hospital in Khartoum. All urine sample (100\%) revealed significant growth four species of bacteria and fungi were isolated.

\begin{tabular}{|l|l|l|}
\hline Gender & Frequency & Percentage $\%$ \\
\hline Male & 60 & $40 \%$ \\
\hline Female & 90 & $60 \%$ \\
\hline Total & 150 & $100 \%$ \\
\hline
\end{tabular}

Table 1: Showing the percentage of males to females.

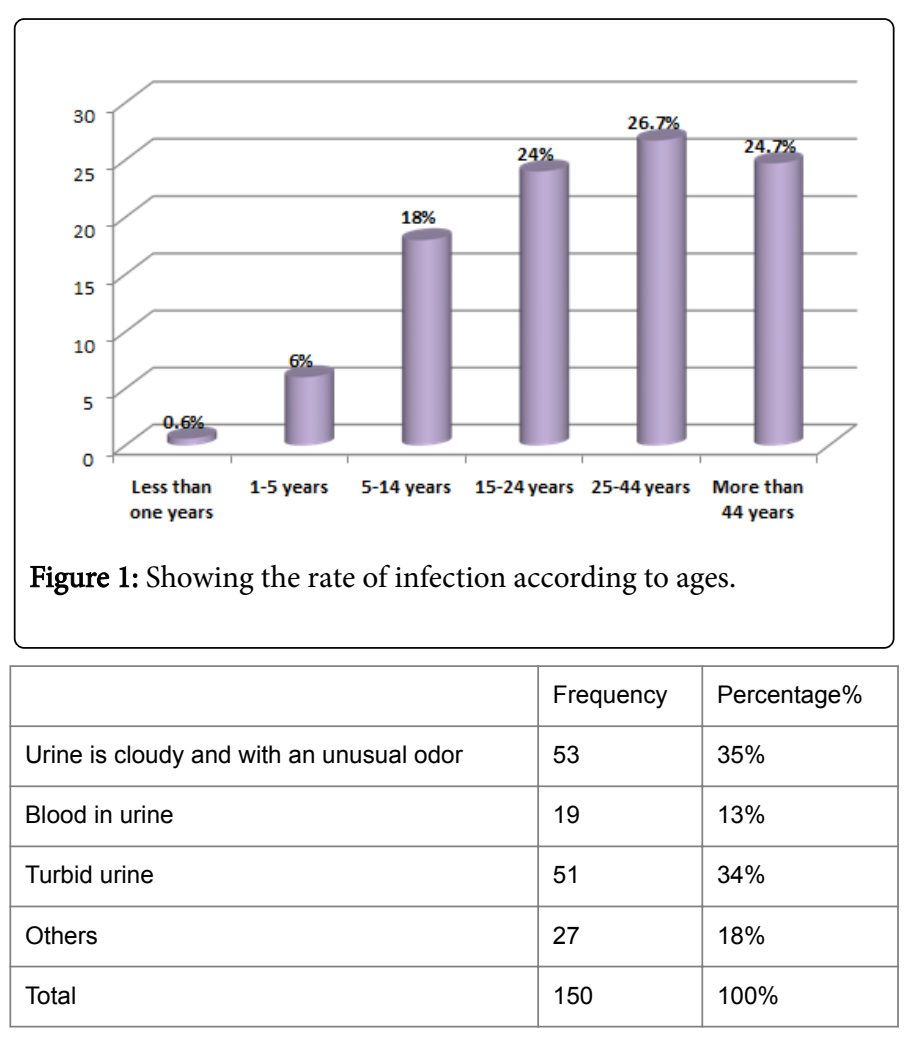

Table 2: Showing macroscopic examination of urine samples.

All the clinical isolates were given code numbers and then purified by streaking plates containing the appropriate selective and differential culture media and then identified on the basis of the results of microscopically staining reaction (Gram stain), culture characteristic 
Page 3 of 4

and biochemical tests. Most of urine appearance showed abnormality and cloudy and unusual odor (Table 2).

The most frequent isolated were E. coli $(57.3 \%), K$. pneumonia (16.7\%), P. aeruginosa (14\%), E. feacalis (4\%), C. albicans (8\%) (Table 3 and 4).

\begin{tabular}{|l|l|l|}
\hline Microorganisms & Frequency & Percentage (\%) \\
\hline E. coli & 86 & $57.30 \%$ \\
\hline K. pneumonia & 25 & $16.70 \%$ \\
\hline P. aeruginosa & 21 & $14 \%$ \\
\hline E. feacalis & 6 & $4 \%$ \\
\hline C. albicans & 12 & $\mathbf{8} \%$ \\
\hline Total & $\mathbf{1 5 0}$ & $\mathbf{1 0 0 \%}$ \\
\hline
\end{tabular}

Table 3: Showing the percentage of microbes isolated from the urine samples.

\begin{tabular}{|l|l|l|}
\hline & Frequency & Percentage\% \\
\hline $\begin{array}{l}\text { The improper cleaning of the anus } \\
\text { area after bowel movement }\end{array}$ & 101 & $67 \%$ \\
\hline $\begin{array}{l}\text { The use of birth control devices } \\
\text { such as diaphragm, condom and } \\
\text { spermicides }\end{array}$ & 13 & $9 \%$ \\
\hline $\begin{array}{l}\text { Suppressing the urge to pass } \\
\text { urine }\end{array}$ & 25 & $17 \%$ \\
\hline $\begin{array}{l}\text { Not drink plenty of water every } \\
\text { day }\end{array}$ & 11 & $7 \%$ \\
\hline Total & 150 & $100 \%$ \\
\hline
\end{tabular}

Table 4: Showing the reason of infection according to questionnaire.

The percentage of UTI was higher among patient improper cleaning of the anus area after bowel movement (67\%) (Table 5).

\begin{tabular}{|l|l|l|l|l|}
\hline \multirow{2}{*}{$\begin{array}{l}\text { Antibiotic } \\
\text { S }\end{array}$} & \multicolumn{3}{|l|}{ Gram negative } & $\begin{array}{l}\text { Gram } \\
\text { positive }\end{array}$ \\
\cline { 2 - 5 } & E. coli & Klebseialla pneumonia & P. aeruginosa & E. feacalis \\
\hline AMP & 98 & 94 & 92 & 80 \\
\hline CIP & 79.7 & 78.7 & 94 & 63.5 \\
\hline CN & 67.5 & 46 & 75 & 81 \\
\hline AMK & 78 & 86 & 69.3 & 30 \\
\hline FEP & 88 & 90 & 91.6 & - \\
\hline IPM & 20 & 50 & 64.6 & - \\
\hline $\begin{array}{l}\text { AMK: Amikacin, AMP: Ampicillin, CIP: Ciprofloxacin, CN: Gentamycin, FEP: } \\
\text { Cefepime, IPM: Imipenem }\end{array}$ \\
\hline
\end{tabular}

Table 5: Antimicrobial resistance pattern (\%) of bacterial agents isolated from urine specimens with selected standard antibiotics.

\section{Discussion}

Urinary tract infection is one of the major diseases that affect people of all age groups, sexes and can be separated into asymptomatic and symptomatic cases based on the pathogenesis of infection [17]. It's the most common postoperative nosocomial infections and the second most common reason for empirical antibiotic treatment.

In the present study all urine sample (100\%) revealed significant growth four species of bacteria and fungi were isolated. the most commonly isolated agents from urinary tract infections vary, almost all of them are caused by single microorganism type. In this study the most frequently isolated microorganism was $E$. coli with a rate of (57\%), followed by $K$. pneumonia with (16.7) and this result is agreement with $[18,19]$. $P$. aeruginosa, $C$. albicans, $E$. feacalis are the next predominant uropathogens isolated. The report of physical parameters of urine specimen shows many of the urine samples was cloudy, few samples were white and red. This reveals that many of the patients have renal diseases and haemoglobinuria. analysis of urine specimen reveals more pus cells indicating that patients were suffering from pyuria.

Multi drug resistance was observed in $90 \%$ of the isolated bacterial uropathogens. This is comparable with the study [19,20,21]. Reasons for such alarming MDR might be inappropriate and incorrect administration of antimicrobial agents as empirical treatment and lack of appropriate infection control strategies, which can cause a shift to increase prevalence of resistant organism in the community [22-25].

\section{Conclusion}

It is concluded that Gram-negative bacilli (Enterobacteracea) were responsible for urinary tract infections. Drink plenty of water daily, wipe from front to back to prevent bacterial around the anus from entering the vagina or urethra, avoid smoking, clean genital area before sexual intercourse, avoid using feminine hygiene sprays and scented douches which may irritate urethra. Increasing rate of resistance to the commonly used antimicrobial agents has been noticed for both gram negative and gram positive isolates. Identifying the pathogen, choosing correct antibiotics, limiting their excess use, improving resistance surveillance systems will help controlling this global problem.

\section{Acknowledgements}

We are grateful to Department of Microbiology, Faculty of Pharmacy and Medical Laboratory Sciences, International University of Africa, Khartoum, Sudan.

\section{References}

1. Gastmeier P, Kampf G, Wischnewski N, Hauer T, Schulgen G, et al. (1998) Prevalence of nosocomial infections in representative German hospitals. J Hosp Infect 38: 37-49.

2. Allegranzi B, Nejad SB, Combescure C, Graafmans W, Attar H, et al. (2011) Burden of endemic healthcare-associated infection in developing countries: systematic review and meta-analysis. Lancet 377: 228-241.

3. Rané A, Dasgupta R (2013) Urinary Tract Infection: Clinical Perspectives on Urinary Tract Infection Elektronisk resurs, London: Springer London.

4. Sandberg TS, Hansson, Nyman J (2014) Urinvägsinfektioner in Läkemedelsboken-Sabiston textbook of surgery: the biological basis of modern surgical practice.

5. Loh K, Sivalingam N (2007) Urinary tract infections in pregnancy. Malays Fam Phys 2: 54-59. 
Citation: Badri AM, Mohamed SG (2017) Clinical Epidemiology and Antibiogram of UTI Patients Attended Different Hospital in Khartoum, Sudan . Clin Microbiol 6: 301. doi:10.4172/2327-5073.1000301

Page 4 of 4

6. Neumann I, Fernanda RM, Moore P (2005) Pyelonephritis in nonpregnant women. Clin Evid 14: 2352-2357.

7. Haider G, Zehra N, Afroze A, Haider A (2010) Risk factors of urinary tract infection in pregnancy. J Pak Med Assoc 60: 213-216.

8. Gunther N, Lockatell V, Jhonson D, Mobly T (2001) In vivo dynamics of type 1 fimbria regulation in uropathgenic Escherichia coli during experimental urinary tract infection. Infec. Immun: 69: 2838-2846.

9. Sahm D, Thornsberry C, Mayfield D, Jones M, Karlowsky J (2001) Multidrug-resistant urinary tract isolates of Escherichia coli: prevalence and patient demographics in the United States in 2000. Antimicrob Agents Chemother 45: 1402.

10. Haryniewicz K, Szczypa K, Sulikowska A, Jankowski K, Betlejewska K, et al. (2001) Antibiotic susceptibility of bacterial strains isolated from urinary tract infections in Poland. J Antimicrob Ther 47: 773-80.

11. Getachew F, Gizachew Y, Yitayih W, Zufan S (2012) The Prevalence and Antimicrobial Susceptibility pattern of Bacterial Uropathogens Isolated from pregnant women. Euro J Exp Bio 2: 1497-1502.

12. Muller AE, Oostvogel PM, Steegers EA, Dörr PJ (2006) Morbidity related to maternal group Bstreptococcaml infections. Acta Obstet Gynecol Scand 85: 1027-1037.

13. Cohen ML (1994) Antimicrobial resistance: prognosis for public health. Trends Microbiol 2: 422-425.

14. Porter IA, Bordie J (1969) Boric acid preservation of urine samples. Br Med J 2: 353-355.

15. Krieg RN, Holt GJ (1984) Bergey's Manual of Systematic Bacteriology 1: 518-538.

16. Tsegay E (2014) Bacterial Profile and Drug Susceptibility Pattern of Urinary Tract Infection in Pregnant Women Attending Antenatal Care at Mekelle Hospital, Mekelle, Northern Ethiopia. Addis Ababa University School of Graduate Studies, (B.Sc.) thesis 15-16.
17. Azubike CN, Nwamadu OJ, Oji RD and Uzoije N (1994) Prevalence of Urinary Tract Infection among School Children in a Nigerian Rural Community. West Afr J Med 13: 48-52.

18. Amin M, Mehdinejad M, Pourdangchi Z (2011) Study of bacteria isolated from urinary tract infections and determination of their susceptibility to antibiotics. Jundishapur J Microbiol 2: 118-123.

19. Beyene G, Tsegaye W (2011) Bacterial Uropathogens in Urinary Tract Infection and Antibiotic Susceptibility Pattern in Jimma University Specialized Hospital, Southwest Ethiopia. Ethiop J Health Sci 21: 141-146.

20. Solomon FB, Wadilo FW, Arota AA, Abraham YL (2017) Antibiotic resistant airborne bacteria and their multidrug resistance pattern at University teaching referral Hospital in South Ethiopia. Ann Clin Microbiol Antimicrob 16: 2-7.

21. Parajuli NP, Acharya SP, Mishra SK, Parajuli K, Rijal BP, et al. (2017) High burden of antimicrobial resistance among gram negative bacteria causing healthcare associated infections in a critical care unit of Nepal. Antimicrob Resis Infect Contr 6: 2-9.

22. Ouno GA, Korir SC, Cheruiyot JC, Ratemo OD, Mabeya BM, et al. (2013) Isolation, Identification and Characterization of Urinary Tract Infectious Bacteria and the Effect of Different Antibiotics. J Nat Sci Res 3: 150-159.

23. Inabo HI, Obanivi HBJ (2006) Antimicrobial susceptibility of some urinary tract clinical isolates to commonly used antibiotics. African J Biotechnol 5: 487-489.

24. Okonko I, Ijandipe L, Ilusanya O, Emmanuel DO, Ejembi J, et al. (2009) Incidence of urinary tract infection among Pregnant women in Ibadan, South-Western Nigeria. Afr J Biotechnol 8: 6649-6657.

25. Rahimkhani M, Khavari-Daneshvar H, Sharif R (2008) Asymptomatic bacteriuria and Pyuria in pregnancy. Acta Medical Iranica 46: 409-412. 